\title{
Exiting the Fantasy Bubble
}

\author{
Erielle Dižon, Simon Fraser University
}

If someone asked my twelve-year-old self if I was a "reader," I would have answered with a resounding "yes." Long before I began reading books on my own, my childhood had a strong foundation on which I gradually developed an interest in stories. My mother and I took turns reading various stories to each other before I had even started kindergarten. The Harry Potter books were some of the most formative stories during this time of my life, though I also vividly remember short, simplified Bible stories that we read. However, reading was not yet my favourite pastime, because I had not yet found the same amount of fun in books as I found in movies and games.

That all changed when I became truly excited about books around Grade 3 after encountering the Deltora Quest fantasy series by Emily Rodda. The worldbuilding engrossed me, but the frequent presence of riddles and puzzles that the protagonists had to solve sealed the deal. My favourite example comes from the second novel, where a giant guarding a bridge threatens to either chop off the protagonist's head or strangle him, depending on whether the protagonist's final statement before dying is true or false. The solution to passing the giant turns out to be a true-false paradox; even now as a student who has studied a bit of logic, I appreciate the effort that went into the riddle's design. By learning how to solve such challenges with the protagonists, I felt much closer to them than I would have without the puzzles. As I got older, some of the other great fantasy worlds that I explored were through reading the His Dark Materials series, The Hobbit and The Lord of the Rings series, and A Game of Thrones (the novel). These books had dangerous worlds, but the comfort I found was in the opportunity to escape my own world and all its uncertainties.

Fantasy grew so comfortable to me that problems of representation within the genre totally flew over my head. I came across "fantasy race" conflicts, but they were so far removed from real race issues that I didn't care to find any meaningful social commentary. I can't remember whether I noticed all the characters I read about in fantasy were white, but, if I did, I would not really care.

ENGL487W - Summer 2021 
I am Asian and grew up with lots of Asian friends and family, but I had no problem with reading white/ambiguous/non-descript/fantasy-ethnicity-thatstands-in-for-white characters so long as I enjoyed the story. Deep down, I associated most books with protagonists of colour with miserable stories about poverty because, while I was growing up, that was the extent of my exposure to diverse literature. Sometimes they were great stories, but they were never fun stories. I will never forget reading $A$ Thousand Splendid Suns by Khaled Hosseini in Grade 8 for significantly different reasons from why I will never forget reading Harry Potter. I would not realize that I was "gatekeeping" my own likeness from appearing in my favourite genre until much, much later.

My feelings about gender also manifested in my reading choices as a young girl. I preferred to follow girls who did "cool" things in fantasy or science fiction because it seemed that the alternatives revolved around romance or other "girly" topics. Unfortunately, I held the impression that girly things could never be cool; no one ever explicitly told me so, but I must have picked up the notion from seeing how poorly our culture reacts to media designed for girls and women. I was also raised with lots of male cousins, male childhood friends, and video games designed for mostly male audiences.

The last reason I considered myself a "reader" was that was how a lot of my family, friends, and teachers perceived me. I genuinely enjoyed reading and learning during elementary and high school, which led others to see me as one of the "smart" children among my classmates. Reading was especially encouraged by my parents and teachers, and my friends were indifferent, though I wonder if I could have been closer to them if I had more "social" hobbies. It's not as if these people were wrong about me; even if you took my hang-ups about other genres as a child/teenager into account, I still read voraciously. It is interesting to reflect on how these expectations from others - which turned into expectations that I had of myself - later influenced me during university.

If someone asked me as a twenty-two-year-old if I am a "reader" today, the answer would be far more complicated. Over the past five years, I have had a harder time processing and absorbing the words on any page. I know that the evolution of social media and texting has affected my attention span, but I also know I have made certain choices that compound the issue. As a double major in English and Philosophy, I am very lucky that I still love what I am learning. Nowadays I largely associate reading with working and studying. The energy that I muster up to read is largely spent on course texts, articles, emails, papers that I 
edit for an academic undergrad journal, and drafts of my own writing. I find it funny and a little sad that I am a Humanities student because of my love of reading, only to have no time or energy to enjoy reading for its own sake.

Sometimes I feel guilty for not reading as widely or as often as some of my peers. Now I can trace this guilt back to when I was identified as "the smart one" by others. I no longer achieved As with minimal effort like I did in high school, and I had a mild-to-moderate case of impostor syndrome. Reassessing some of my priorities in life helped me deal with this feeling. I explored new opportunities outside of school such as co-op and volunteering and picked up new hobbies including cycling and piano. It was well past time to let go of my need to feel like "the smart one." While these activities are not directly related to reading, I think they gave me enough time and distance to develop a more balanced view of my relationship to it.

Perhaps I am still a "reader," but of a different kind. I might not have the free time to read as I had during my childhood and adolescence, but I was never as critical of my reading as I am today. I have not bought a new book to read for leisure in years, but I have made better use of libraries and recently started listening to audiobooks. I began considering audiobooks as a legitimate option thanks to my best friend. One evening, after I complained to her about how I could no longer read for fun, she decided to read entire chapters of her favourite book The Rule of Three by Eric Walters (a realistic thriller type of novel) to me over the phone. As unorthodox as it was, having someone read stories aloud to me broke through the "reading block" I had been experiencing for years. I think I will always have internalized prejudices to work past, but at the very least I have left the notion that girly things could never be cool in the dust. Some YA fantasy and sci-fi novels I enjoyed as a teenager were written with a female audience in mind, so there is no use pretending I was "unique" for largely avoiding romance. It might never be my favourite, yet my friend (the same one who was zany enough to read aloud to me) and I have had great fun imagining what Twilight would have looked like if it were better written. We are only halfway through Rule of Three and are currently too busy to engage in such antics again, but I would have never experienced these things if I was not willing to step outside my fantasy bubble.

Someday I want to teach literature myself. I want to help students not only feel more included in the stories we read, but also feel equipped to navigate murky waters such as how to think about authors whom we know are prejudiced, how to talk about racism, and how to reflect on discomfort. I am forever grateful to my

ENGL487W - Summer 2021 
family and my own teachers for setting me on this path, but, if I become a teacher, I would do my students a disservice if I just stuck with what was pleasing and comfortable. My time at university showed me the benefits of teaching uncomfortable texts in a constructive manner: improved critical thinking, empathy, and writing skills, to name a few. High school and elementary students deserve similar opportunities.

\footnotetext{
(c) (1) $\ominus$ This work is licensed under a Creative Commons AttributionEY NC ND NonCommercial-NoDerivatives 4.0 International License.
}

(C) Erielle Dizon, 2021 